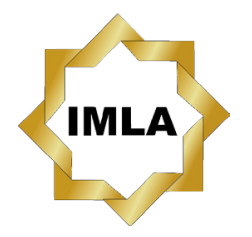

\title{
KAJIAN GENDER PADA NOVEL KARYA NAWAL EL SAADAWI DAN SUTAN TAKDIR ALISJAHBANA
}

\author{
Deffi Syahfitri Ritonga \\ Universitas Sumatera Utara \\ Email: fitria.anwar@gmail.com
}

Naskah diterima: 18 Februari 2016, direvisi: 12 Maret 2016, disetujui: 20 April 2016.

\begin{abstract}
This study aimed at analyzing two popular novels in the light of gender perspective, namely Mudhakkirât at-Thabîbah written by Nawal el-Saadawi and Layar Terkembang by Sutan Alisjabana. The qualitative research on women in this literary genre was conducted by a qualitative comparative approach between the two novelists of different genders and socio-cultural backgrounds. The theory used to comprehend both literary works was the feminist-literary critical theory. To read and analyze the data, the researcher used content analysis. This study concluded that the negative views on women were resulted by misunderstanding of religious teachings and cultural construction of gender bias that caused the weak position of women in society and religion. Women were visibly misinterpreted, either in a pattern of sexism or their relationships with men. This study indicated the deconstruction of women by the writers' perspectives represented in literature works - i.e. novels.
\end{abstract}

Kata kunci: gender bias, literary works, novels, Nawal El Saadawi, Sutan Takdir Alisjahbana

\section{Abstrak}

Penelitian ini bertujuan untuk menganalisis novel karya Mudhakkirât at-Thabîbah karya Nawal El Saadawi dan Layar Terkembang karya Sutan Takdir Alisjabana dalam perspektif kajian gender. Penelitian kualitatif bergenre perempuan dalam sastra ini dilakukan dengan pendekatan kualitatif komparatif antara kedua novelis yang berbeda jenis kelamin dan latar belakang sosial budaya keduanya. Teori yang digunakan untuk memahami kedua karya sastra tersebut adalah teori kritik sastra feminis. Pembacaan dan pemaknaan data penelitian dilakukan dengan analisis isi. Penelitian ini berkesimpulan bahwa pandangan negatif yang melingkupi sosok perempuan sebagai akibat dari kesalahpahaman terhadap ajaran agama dan konstruksi budaya bias gender menjadi penyebab lemahnya posisi perempuan dalam pandangan masyarakat dan agama. Sosok perempuan cenderung disalahapahami, baik dalam pola kebertubuhan maupun pola relasinya dengan laki-laki. Hasil penelitian ini memperlihatkan dekonstruksi sosok perempuan melalui sudut pandang pengarang laki-laki dan perempuan yang direpresentasikan melalui karya sastra (novel).

Kata kunci: bias gender, karya sastra, novel, Nawal El Saadawi, Sutan Takdir Alisjahbana

How to Cite : Ritonga, Deffi Syahfitri. "KAJIAN GENDER PADA NOVEL KARYA NAWAL AL SAADAWI DAN SUTAN TAKDIR ALISJAHBANA" Arabiyat : Jurnal Pendidikan Bahasa Arab dan Kebahasaaraban [Online], Volume 3 Number 1 (30 Juni 2016)

Permalink/DOI: http://dx.doi.org/10.15408/a.v3i1.2976 


\section{Pendahuluan}

Anggapan bahwa laki-laki secara sosial dan biologis lebih superior dibanding perempuan memang telah memunculkan isu gender. ${ }^{1}$ Streotipe buruk dan marjinalisasi posisi perempuan dalam dunia yang "dikuasai" laki-laki, menjelma melalui anggapan bahwa perempuan itu lemah, bodoh, barbar, tidak beradab, irasional, aneh, mistis, berbeda, penurut, penggoda, pelengkap laki-laki, penuntut, cerewet, dan emosional. ${ }^{2}$ Anggapan ini semakin negatif karena diperburuk oleh kesalahpemahaman terhadap ajaran agama $^{3}$ dan budaya yang banyak direpresentasikan melalui narasinarasi timpang yang banyak ditulis oleh laki-laki untuk melegalkan kekuasaannya. ${ }^{4}$ Dalam hal ini, Sukron Kamil berpendapat bahwa problem peminggiran perempuan tidak hanya karena masalah struktural, tetapi juga karena persoalan kultural, seperti pengaruh kepercayaan dan pemahaman keagamaaan. Pemahaman parsial dan literal terhadap teks-teks Alquran dan hadits tampaknya turut mempengaruhi peminggiran perempuan di negara-negara Muslim. Wacana Islam dalam sejumlah kitab fikih misalnya, tidakbanyak menguntungkan perempuan, bahkan pada bagian-bagian tertentu cenderung mendiskreditkan

\footnotetext{
$1 \quad$ Abidemi R. Asiyanbola, "Patriarchy, male dominance, the role and women empowerment in Nigeria," Paper submitted for presentation as poster at the International Union for the Scientific Study of Population (IUSSP/UIESP) XXV International Population Conference Tours, France, 2005, h. 18-23, h. 262 .

2 Rosemary Putnam Tong, Feminist Thought,

3 Anthonia M. Essien dan Donatus P. Ukpong, "Patriarchy and Gender Inequality: The Persistence of Religious and Cultural Prejudice in Contemporary Akwa Ibom State, Nigeria," International Journal of Social Science and Humanity, Vol. 2, No. 4, (2012), h. 286.

$4 \quad$ Anne Barbeau Gardiner, "Feminist Literary Criticism: From Anti-Patriarchy to Decadences, h. 395.
}

perempuan. ${ }^{5}$

Wacana gender yang sejatinya merupakan konstruksi sosial dan kultural perihal peran laki-laki dan perempuan di tengah kehidupan sosial, justeru diselewengkan oleh laki-laki sebagai kodrat Tuhan yang harus diterima secara taken for granted. ${ }^{6}$ Perempuan dengan segala bentuk konstruksi negatif yang dialamatkan masyarakat kepadanya mau tidak mau harus menjadi entitas yang tunduk pada kuasa patriarki. Menurut Shannon Gilreath, sistem patriarki yang berlaku dalam kehidupan masyarakat menjadi alasan kuat bagi lakilaki untuk menyubordinasi perempuan. ${ }^{7}$ Dalam masyarakat yang menganut budaya patriarki, perempuan sudah tidak memiliki peran untuk berinteraksi dalam ruang publik. Eksistensi perempuan hanya sebatas pelengkap bagi langgengnya kekuasaan laki-laki, sebab hak-haknya telah pula diperjualbelikan sehingga kedudukan perempuan menjadi tidak lagi berguna. ${ }^{8}$

Relasi yang tidak seimbang dalam pola kehidupan laki-laki dan perempuan menjadi pembuka awal Nawal El Saadawi maupun Sutan Takdir Alisyahban (STA) mengekspresikan pemikiranpemikirannya berkenaan dengan perbaikan status perempuan (emansipasi) dalam masyarakat dan budaya yang menganut kepercayaan patriarki demi tercapainya kesetaraan gender. Mengacu

5 Sukron Kamil, Syari'ah Islam dan HAM: Dampak Perda Syari'ah terhadap Kebebasan Sipil, Hak-Hak Perempuan, dan Non-Muslim (Jakarta: CSRC, 2007), h. 38.

6 Sukidi, Teologi Inklusif Cak Nur (Jakarta: Kompas, 2008), h. 160.

7 Shannon Gilreath, "Patriarchal Religious, Sexuality, and Gender: An Introductory Essay, h. 201.

8 Bell Hooks, "Understanding Patriarchy," 1. http://imaginenoborders.org/pdf/zines/UnderstandingPatriarchy.pdf, diakses 21 Januari 2016, pukul 10.11 WIB. 
pada pendapat Beauvoir yang menyatakan bahwa perempuan tidak dilahirkan sebagai perempuan tetapi untuk menjadi perempuan, menjadikan laki-laki bebas mengonstruksikan identitas perempuan semaunya, yang berakibat pada laki-laki menjadi "Sang Diri" (yang mempunyai kesadaran) dan perempuan menjadi "Liyan" (yang diobjeki oleh Diri). Dalam kasus Mudhakkirât Thabîbah karya El Saadawi dan Layar Terkembang karya STA, posisi perempuan sebagai objek tersubordinasi yang ditempeli dengan beragam peran-peran tradisional tak ramah gender terlihat dari narasi-narasi yang diungkapkan sang tokoh utama dalam kedua novel ini yakni, tokoh Aku dan tokoh Tuti. Setelah dilakukan pembacaan secara mendalam dan menyeluruh terhadap novel Mudhakkirât Thabîbah dan Layar Terkembang serta menilik dari bentuk kesadaran diri yang dimiliki ketiga tokoh yang telah dibahas di atas, terdapat perbedaan yang sangat kontras dalam cara El Saadawi dan STA menyuarakan pembebasan bagi perempuan.

Artikel ini bertujuan menganalisis isi novel Mudhakkirât Thabîbah karya Nawal El Saadawi dan Layar Terkembang karya Sutan Takdir Alisjahbana sebagai penggambaran bagaimana sosok (citra) perempuan direpresentasikan dalam karya laki-laki dan perempuan. Kedua buku yang dihasilkan oleh dua jenis kelamin berbeda dengan pemikiran berbeda dalam penelitian ini menjadi menarik, karena keduanya samasama membentuk sosok perempuan ideal versi mereka masing-masing dengan segala kelebihan dan kekurangannya, di saat ada begitu banyak kepercayaan berkembang yang meyakini hanya perempuanlah yang dapat menghayati dunia perempuan secara utuh.
Dalam tekssastra,pengarangperempuan boleh jadi menciptakan perempuan yang tertindas dengan streotipe-streotipe lainnya yang tidak memenuhi norma masyarakat patriarkal. ${ }^{9}$ Namun, sangat dimungkinan dalam karya pengarang laki-laki terdapat sosok-sosok perempuan yang kuat dan terang-terangan mendukung nilai-nilai feminisme. Akan tetapi, sosok perempuan yang direpresentasikan laki-laki dalam karyanyasebaikapapuntetaplah merupakan hasil pencintraan dari pemikiran laki-laki terhadap perempuan, seperti tokoh Tini yang diciptakan Armijn Pane dalam novel Belenggu, Srintil ciptaan Ahmad Tohari dalam Ronggeng Dukuh Paruk, juga tentunya Tuti dan Maria sebagai hasil pencitraan Alisjahbana dalam novel Layar Terkembang. Artikel ini diharapkan dapat memberikan kontribusi dalam pengembangan kajian sastra, khususnya kritik sastra feminis.

\section{Metode Penelitian}

Penelitian ini merupakan penelitian kualitatif dengan menggunakan analisis isi. ${ }^{10}$ Penelitian ini dilakukan dengan prosedur: penggumpulan, analisis, dan penyajian data. Penggumpulan data mengacu pada sumber primer dan sumber sekunder. Sumber primer yang menjadi acuan utama dalam penelitian adalah novel Mudhakkirât Thabîbah dan Layar Terkembang. Sedangkan sumber sekundernya berupa buku-buku karya El Saadawi maupun STA lainnya, hasil-hasil penelitian sebelumnya dan literatur lain dengan tema yang sama dalam

\footnotetext{
9 Ali Imran A-Ma'ruf, "Dekonstruksi Citra Keperempuanan dalam Sastra: dari Budaya Lokal hingga Global," https://publikasiilmiah.ums.ac.id/ bitstream/handle/, diakses 31 Maret 2016, pukul 10.12 WIB.

10 Penjelasan mengenai penelitian kualitatif dapat dilihat dalam, Sudarnoto, Metodologi Penelitian Filsafat (Jakarta: Rajawali Press, 1996) h. 62; Nyoman Kutha Ratna, Teori, Metode, dan Teknik, h. 46-47
} 
berbentuk buku, jurnal, artikel, makalah, dan encyclopedia. Pengumpulan data dilakukan dengan pembacaan secara utuh dan menyeluruh terhadap sumber data primer maupun sumber sekunder yang mendukung data primer sehingga dipahami ide dan gagasan pengarang dengan baik. Teknik pembacaan yang digunakan dalam penelitian ini adalah close reading. ${ }^{11}$

Data yang telah dibaca secara menyeluruh lalu diklasifikasi dan diidentifikasi menurut jenisnya masingmasing untuk kemudian dianalisis. Metode analisis data yang digunakan dalam penelitian ini adalah metode kritik sastra feminis. Metode kritik sastra feminis dipahami sebagai cara di mana "teks-teks sastra dibaca, diajarkan, dan dievaluasi". ${ }^{12}$ Metode kritik sastra feminis dalam penelitian ini dilakukukan dengan cara (1) mengidentifikasi unsur-unsur novel, (2) mengklasifikasikan unsur-unsur tersebut menurut fokus yang hendak dikaji, yaitu unsur yang mengacu pada penggambaran sosok (citra) perempuan dalam pandangan Nawal El Saadawi dan Sutan Takdir Alisjahbana sebagaimana termaktub dalam novel mereka, (3) data-data tersebut kemudian dianalisis untuk melihat bagaimana Nawal El Saadawi dan Sutan Takdir Alisjahbana merepresentasikan sosok perempuan dalam karya mereka, dan terakhir (4) menyajikan dan menyimpulkan hasil penelitian dengan menggunakan metode deskriptif komparatif.

11 Close reading yang dimaksudkan di sini ad lah membaca secara teliti seluruh data yang hendak diteliti dengan melihat konteks historis dan konteks tekstualnya. Lihat, Brummett. B., Techniques of Close Reading (Los Angeles: SAGE Publication, 2010), h. 9-10.

12 Christian Bauer, "Stereotypical Gender Roles and their Patriarchal Effects in A Streetcar Named Desire," http://www.diva-portal.org/smash/get/ diva2:496855/FULLTEXT01.pdf (2012): h. 2-3.

\section{Temuan dan Diskusi}

\section{Sosok Perempuan dalam Pandangan Masyarakat Umum}

Praktik budaya patriarkis yang berkembang dalam kehidupan masyarakat, utamanyayangberkaitan dengan perbedaan peran dan relasi antara perempuan dan laki-laki, telah menjadi permasalahan pelik yang tak kunjung usai sejak beberapa abad lalu. Praktik ini disadari atau tidak, telah mengonstruksikan manusia dalam sistem kelas-kelas "lelaki dan perempuan". ${ }^{13}$ Satu pihak menjadi superior dan pihak lainnya menjadi inferior. ${ }^{14}$ Pihak yang superior memiliki kecenderungan untuk menyubordinasi pihak inferior. ${ }^{15}$ Perempuan sebagai yang inferior digambarkan sebagai makhluk yang tidak berjiwa. ${ }^{16}$ Freud $^{17}$, Lacan $^{18}$, Aristoteles ${ }^{19}$,

13 Abeda Sultana, "Patriarchy and Women's Subordination: A Theoretical Analysis," The Art of Faculty Journal (Juli 2010-Juni 2011), h. 2-3; Maureen Kambarani, "Feminity, Sexuality and Culture: Patriarchy and Female Subordination in Zimbabwe," University Fort Here South Africa (2006), h. 1-2.

14 Nína Katrín Jóhannsdóttir, "Patriarchy and The Subordination of Women: From A Radical Feminist Point of View," Silligum Universitatis Islandiane (Mei, 2009), h. 6.

15 Steven R.Tracy, "Pathriarchy and Domestic Violence: Challenging Common Misconception," JETS, Vol.50, No.3 (September, 2007), h. 576-577.

16 Johanna Martina Wood, "Patriarchy, Feminism and Mary Dale: A Systematic Theological Enquiry Into Daly's Engagement With Gender Issue in Christian Theology," Disertasi University South Africa, tt, h. 31.

17 Sofe Ahmad, "Sigmund Freud's Psychoanalityc Theory Oedipus Complex: A Critical Study With Reference to D.H. Lawrence's Son and Lovers," International Journal of English and literature, Vol.3, No.3 (2012), h. 64-65.

18 Christine Everingham, "Lacan's Gap: Sexual Identity and The Problem Connectedness," Journal of Interdiciplinary Gender Studies, Vol.1, No.2 (1996): 118-120; Toril Moi, "From Feminity to Finitude: Freud, Lacan, Feminism, Again," Journal of Women in Culture and Society (Signs), Vol.29, No.31 (2004), h. 842.

19 Peter Eichman, "Sex, Blood, and Soul: The Transmission of Form in Aristotle's Biology," http:// 
Plato, ${ }^{20}$ Aquinas, ${ }^{21}$ memberikan pernyataan yang hampir senada mengenai perempuan, bahwa perempuan adalah laki-laki yang tidak lengkap, tidak berakal, serta bukan diciptakan sebagai produksi pertama, melainkan keberadaannya bergantung pada laki-laki.

Konsep-konsep bias gender yang dikemukakan oleh banyak ilmuwan, sejarawan, filosof, yang kemudian diyakini dan dijunjung tinggi oleh masyarakat luas, menjadikan perempuan dalam masyarakat patriarki tidak lagi memiliki peran untuk eksis di ruang ruang publik. Hak kebertubuhannya telah dirampas dan diperjualbelikan, sosok-sosok perempuan ini kemudian hanya dianggap tidak lebih dari sekadar pelengkap bagi langgengnya eksistensi laki-laki. ${ }^{22}$ Dalam catatan sejarah, kehidupan perempuan dalam berbagai agama dan kebudayaan, mulai dari budayabudaya kuna sampai modern selalu diwarnai dengan praktikketidaksetaraangender.Pada tahap awal, sejarah penindasan perempuan sering dikaitkan dengan jenis kelamin: jenis kelamin perempuan dipandang sebagai kelas bawahan yang harus tunduk pada dominasi laki-laki.

Gagasan patriarki ditandai dengan penekanan dan eksploitasi terhadap perempuan. $^{23} \quad$ Sebagian besar sejarah menunjukkan, peran perempuan baik dalam

echodin.net/papers/phil515/aristotle.pdf (Mei, 2007), h. 2.

20 Patricia M. Lines, "Shockling The Imagination: Education for Virtue in Plato and Rosseau," Humanitas, Vol.XXII, No.1-2 (2009), h. 4143.

21 St. Thomas Aquinas, Summa Theologica (Ohio: Benziger Bros, 1947), h. 19-21.

22 Asep Deni Saputra, "Perempuan Subaltern dalam Karya Sastra Indonesia Poskolonial," Literasi, Vol.1, No.1 (2011), h. 18.

23 Gayle Rubin, "The Traffic in Women: Notes on the 'Political Economy' of Sex," dalam Joan W. Scott (ed), Feminism and History (New York: Monthly Review Press, 1996), 52, h. 105. ruang privat maupun publik, diremehkan, ditolak,dandiabaikan. ${ }^{24}$ Sejarahmenunjukan bagaimana agama dan kemajuan teknologi bekerja sama untuk membentuk sistem yang menyubordinasi perempuan. ${ }^{25}$ Sikap patriarkal yang digambarkan oleh sejarah melalui berbagai tradisi, agama, dan kepercayaan, menjadikan kuasa patriarki bagai mata rantai dari kekuatan maskulin laki-laki untuk membentuk stigmastigma negatif berkenaan dengan sosok perempuan.

Contoh konkret dari stigma negatif yang dibangun oleh agama dan tradisi terhadap sosok perempuan adalah dugaan penciptaan Hawa dari tulang rusuk Adam, yang telah berhasil membuat perempuan menempati posisi rendah, bukan saja di lingkungan keluarga dan gereja dalam konteks umat Kristiani, tetapi juga dalam pandangan masyarakat secara umum dan luas. Kepercayaan akan penciptaan Hawa dari tulang rusuk Adam telah melahirkan konsep bias gender lainnya yang meyakini bahwa perempuan adalah pemikul dosa abadi karena telah mendatangkan malapetaka bagi seluruh laki-laki akibat dari bahasa tubuhnya yang suka merayu dan menggoda laki-laki. Oleh karena itu, perempuan hanya dilihat sebagai makhluk kedua yang diciptakan untuk memuaskan nafsu laki-laki. ${ }^{26}$

Keluarga sebagai lembaga terkecil dalam sebuah komunitas masyarakat dan budaya juga memiliki peranan penting dalam membentuk sosok perempuan

24 Carolyn DeArmond Blevins, Women in Christian History: A Bibliography (Macon, Georgia: Mercer Univ Press, 1995).

25 Margaret Gounsolin, “Women's Rights and Women's Rites: Religion at the Historical Root of Gender Stratification," Electronic Journal of Sociology, ISSN: 11983655 (2005), h. 3.

26 Johanna Martina Wood, "Patriarchy, Feminism and Mary Daly, tt, h. 31. 
tersubordinasi yang selalu diliputi oleh pandangan-pandangan negatif. Sebagai sebuah lembaga, keluarga menjadi tempat pertama mensosialisasikan perbedaan peran melalui jenis kelamin. Dalam tradisi Sunni, laki-laki diasosiasikan sebagai superior, pencari nafkah dan sebagai kepala keluarga. sementara itu, perempuan diajarkan untuk membantu pekerjaan rumah tangga secara taat dan patuh. Perbedaan konstruksi ini kemudian menjadi penyebab subordinasi dan diskriminasi perempuan, sehingga masyarakat cenderung memandang perempuan sebagai makhluk seksual dan bukan sebagai manusia. ${ }^{27}$ McDowell dan Rosemary Pringle dalam Defining women: Social Institutions and Gender Divisions lebih lanjut menyatakan bahwa perempuan tidak hanya terus didefinisikan sebagai entitas yang lebih lemah dari laki-laki, tetapi didefinisikan juga sebagai dependen dan bawahan laki-laki. Akibatnya, perempuan diasosiasikan untuk memperoleh sifatsifat yang sesuai dengan mereka seperti, kelembutan, lemah, kurang cerdas, pasif, ketergantungan pada laki-laki, tunduk dan selalu berusaha menyenangkan lakilaki. ${ }^{28}$

Dalam keluarga, anak laki-laki lebih disukai dan diharapkan dibanding anak perempuan. Bahkan, anak laki-laki cenderung suka memerintah perempuan. Meskipun bukan sebagai anak yang pertama lahir dalam keluarga, laki-laki secara otomatis dianggap sebagai kepala keluarga yangharusmelindungidan menjaga saudarasaudara perempuannya. Sebaliknya, anak

27 Charvet, J., Modern Ideologies: Feminism (London: J.M. Dent and Sons Limited, 1982).

$28 \quad$ L, McDowell dan Rosemary Pringle, Defining women: Social Institutions and Gender Divisions (Oxford: Polity Press, 1992), h. 5-6. perempuan didiskriminasi atas fakta bahwa akhirnya dia harus menikah dan bergabung dengan keluarga lain, sementara anak laki-laki menjamin kelangsungan hidup nama keluarga melalui pernikahan dengan membawa anggota keluarga lain ke dalam keluarganya. ${ }^{29}$ Keluarga sebagai kelompok sosial terkecil juga menjadi tempat yang rentan bagi kekerasan terhadap perempuan. Rosemary Radford Reuther dalam The Western Religious Tradition and Violence Againts Women in Home menyatakan, "pemukulan terhadap istri dan anak-anak (khususnya perempuan) serta berbagai bentuk kekerasan dalam rumah tangga lainnya, merupakan bukti nyata dari tradisi patriarkal dan status subordinat perempuan. ${ }^{30}$

\section{Sosok Perempuan dalam Mudhakkirât Thabîbah dan Layar Terkembang}

Novel Mudhakkirât Thabîbah lahir dari kesadaran reflektif El Saadawi terhadap fenomena peminggiran perempuan yang terjadi dalam masyarakatnya. Kondisi sosio-kulturalnya yang tidak ramah perempuan dan cenderung mensubordinasi mereka dengan menggunakan berbagai alasan seperti agama, sistem sosial, sejarah, pendidikan, agama, keluarga dan ekonomi, mengilhami El Saadawi untuk merefleksikan realitas sosial yang ditemuinya di masyarakat dalam narasi estetis sebagai bentuk protesnya terhadap budaya mapan. El Saadawi dalam Mudhakkirât Thabîbah bercerita banyak tentang pola relasi laki-laki dan perempuan

29 Maureen Kambarani, Feminity, Sexuality, and Culture, h. 4.

30 Rosemary Radford Ruether, "The Western Religious Tradition and Violence against Women in the Home," dalam Joanne Carlson Brown and Carole R. Bohn (ed), Christianity, Patriarchy, and Abuse (Cleveland, OH: Pilgrim, 1989), h. 31. 
dalam masyarakatnya yang patriarkis sesuai pandangan dunianya yang digambarkan melaluipemikiran dan perilaku tokoh Aku. Melalui tokoh Aku, El Saadawi melancarkan serangan-serangannya terhadap budaya mapan yang berkembang di masyarakatnya melaluiberbagaipersoalanyangdisorotinya. Sebagai titik pusat dalam keseluruhan narasinya, El Saadawi menempatkan tokoh Aku sebagai pihak oposisi yang memiliki kecenderung berlebih dan bahkan berseberang dengan segala macam bentuk kebudayaan dan ajaran agama yang mengacu pada subordinasi terhadap perempuan.

Sebagai tokoh sentral sekaligus pencerita dalam novel Mudhakkirât Thabîbah, tokoh aku tampil sebagai satu-satunya tokoh yang memperjuangkan emansipasi perempuan, meskipun bukan satu-satunya yang mendukung dan menghargai potensi perempuan. Tokoh Aku kecil hingga dewasa digambarkan sebagai seseorang yang membenci keperempuanannya. Kondisinya yang terlahir sebagai perempuan di tengah keluarga dan masyarakat yang menganut paradigma patriarkis menjadikan gerak dan segala macam tingkahnya menjadi sorotan. Pembedaan kontras yang terjadi antara dirinya dan saudara-saudara lelakinya adalah hal paling tidak masuk akal yang selalu menghantui kehidupan tokoh aku. Ia tidak mengerti mengapa ibunya hanya diam saja apabila saudara lekakinya bangun tidur boleh saja pergi tanpa harus susah payah merapihkan tempat tidur. Ia juga tidak mengerti mengapa saudara lelakinya boleh mengambil potongan daging paling besar, memakannya secara lahap dan meminum kuah sup dengan keras-keras. Mengapa saudara laki-lakinya bebas melompatlompat dan bermain ke luar sesuka hati mereka tanpa takut dimarahi ibunya.
Ketidakmengertian tokoh Aku sama seperti tidak mengertinya ia akan perlakuan ibunya terhadapnya yang serba terkontrol dan tidak boleh ini dan itu. Ibunya akan akan marah besar jika mendapati gaun yang dikenakan tokoh Aku tersingkap sedikit di atas paha, atau ketika tokoh Aku sibuk dengan dunianya sendiri dan mengabaikan tugas-tugas rumah seperti memasak yang selalu ditekankan ibunya sebagai pekerjaan utama perempuan setelah menikah selain mengurus rumah, suami, dan anak.

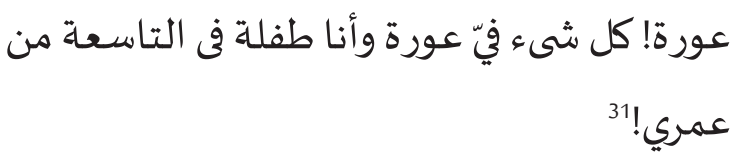

"Memalukan! Segala dalam diriku memalukan, padahal ketika itu aku hanyalah seorang anak perempuanyang baru berumur sembilan tahun".

Hal-hal sederhana seperti yang dituturkan tokoh Aku dalam pola pembagian peran tradisional maupun perlakuan berbeda antara laki-laki dan perempuan dalam keluarga bukanlah hal baru. Keluarga sebagai lembaga terkecil dalam komunitas masyarakat berpengaruh besar dalam menyosialisasikan perbedaan peran melalui jenis kelamin. Pembedaanpembedaan ini yang kemudian menimbulkan ketidaksetaraan gender dalam relasi laki-laki dan perempuan. Kepercayaan umum yang berkembang dalam masyarakat utamanya yang menganut patriarki sejak zaman pra-sejarah sampai zaman modern mendemonstrasikan pola pikir yang sama berkaitan dengan perempuan dan lakilaki. Laki-laki selalu diasosiasikan sebagai jenis kelamin superior, pencari nafkah, pelindung, kepala keluarga, tangguh, kuat

31 Nawal El Saadawi, Mudhakkirāt Țabībah (Beirut: Dār al-Ma'ārif, 1960), h. 6. 
dan bertanggung jawab. Sementara itu, perempuan dikonstruksikan dengan sikap yang lemah, penakut, gampang terpedaya, sehingga mereka lebih cocok dengan pekerjaan rumah seperti memasak, membersihkan rumah, mengurus anak, dan peran-peran tradisional lainnya.

Perempuan juga diharuskan untuk tunduk dan patuh dalam kuasa laki-laki serta harus menyembunyikan segala keinginan diri mereka demi memenuhi keinginan pihak-pihak lain, utamanya lakilaki. Kepercayaan ini pada akhirnya bukan hanya merugikan perempuan secara fisik yang ditandai dengan ketidakbebasan mereka melakukan hal-hal yang biasa dikonstruksikan maskulin, tetapi juga secara psikologis yang menyebabkan banyak perempuan terlarut dalam konstruksiyangtelah ditanamkan keluarga, masyarakat, dan budaya sejak mereka kecil, sehingga tidak menyadari kooptasi gender yang menimpa diri mereka dan beranggapan bahwa perbuatan menentang pembagian peran tradisionalis yang telah mapan sebagai perbuatan amoral yang melanggar norma-norma dan kepercayaan umum dalam masyarakat. ${ }^{32}$

Sikap tokoh Aku yang mengajukan pertanyaan atas kecenderungan keluarganya mengistimewakan anak laki-laki dibanding anak perempuan mengisyaratkan bahwa anggapan perempuan sebagai the second sex, liyan, the other, second creation, ataupun second class citizen masih bertahan di masyarakat.

32 Kondisi perempuan yang tidak menyadari bentuk opresi yang menimpa diri mereka dalam relai dengan dengan laki-laki dan justru menikmatinya sebagai sesuatu yang bukan permasalahan oleh Piere Boudieau dalam Practical Reason: On the Theory of Action sebagai salah satu bentuk kekerasan simbolik (symbolic violence). Lebih lanjut lihat: Piere Boudieau, Practical Reason: On the Theory of Action (California: Standford Unversity Press, 1998), h. 102.
Kecenderungan mengistimewakan anak laki-laki dibanding anak perempuan tidak hanya terjadi di negara-negara Arab dan Timur Tengah, Mesir khususnya, tetapi juga di negara-negara lain dengan berbagai kebudayaan dan tradisi seperti Indonesia, khususnya yang masih menganut kepercayaan tradisional. Dalam keluarga-keluarga tradisional maupun modern (meski jumlahnya tidak sebanyak keluarga tradisional), anak laki-laki lebih disukai dan diharapkan dibanding anak perempuan sebab kedudukan mereka sebagai penjamin kelangsungan hidupnama keluarga. Bahkan, anak laki-laki cenderung memerintah anak perempuan sebagai akibat dari pembagian peran tradisional yang telah ditanamkan sejak lahir bahwa laki-laki lebih superior dibanding anak perempuan. Sebaliknya, anak perempuan terus terdisikriminasi atas fakta bahwa ia lemah, mudah terpengaruh, dan tentu saja tidak bisa melanjutkan nama keluarga.

Pola pembagian peran tradisional dalam hubungan keluarga bukanlah satu-satunya persoalan yang disoroti El Saadawi dalam Mudhakkirât Thabîbah. Sebagai seorang feminis sosialis yang hampir radikal, El Saadawijuga tampaknya tertarikmengkritisi ajaran agama yang diangapnya misoginis. Maraknya penafsiran misoginis dalam Alquran dan hadith Nabi SAW dianggap El Saadawi sebagai bentuk kebencian lakilaki terhadap perempuan. Agama yang sejatinya mengajarkan kesetaraan justru disalahtafsirkan untuk melanggengkan kekuasaan lelaki atas perempuan. Salah satu yang menjadi perhatian El Saadawi dalam Mudhakkirât Thabîbah adalah fenomena menstruasi yang menghinggapi kaum perempuan setiap bulannya ketika mereka telah memasuki usia dewasa. Hal ini dilukiskan dalam penuturan tokoh 
Aku yang telah menginjak usia sembilan tahun pada suatu ketika dikejutkan dengan perilaku tubuhnya yang tidak biasa. Darah berwarna merah pekat keluar dari tubuhnya tanpa sesuatu sebab yang jelas. Kondisi pendarahan yang tak biasa ini menimbulkan ketakutan luar biasa dalam diri tokoh Aku. Berpuluh kemungkinan hinggap di kepalanya berkenaan dengan perilaku tubuhnya yang abnormal tersebut, sampai kemudian ibu tokoh Aku dengan wajah berseri-seri menjelaskan bahwa pendarahan pada perempuan adalah kondisi normal yang menandai fase di mana perempuan tersebut telah memasuki usia dewasa. Pendarahan yang lazim disebut haid ini akan berlangsung setiap bulan pada perempuan normal menurut siklusnya.

Tokoh Aku yang sejak awal telah membenci sifat kewanitaan dalam dirinya beserta seluruh perlakuanyang dianggapnya tidak setara antara dia dan saudara-saudara laki-lakinya tidak bisa mengerti mengapa perempuan harus melewati sesuatu yang buruk dan menjijikkan hanya untuk memasuki usia dewasa. Pernyataan ini terangkum dalam narasi El Saadawi sebagai berikut:

$$
\begin{aligned}
& \text { ألم تكن هناك طريقة أخرى تنضج بها البنات غير } \\
& \text { هذه الطريقة اللوثة؟ أيمكن الإسـان أن يعيش } \\
& \text { أياما تحت سيطرة عضلاته اللإرادية الغاشمة ؟ لا } \\
& \text { بد أن الله يكره البنات فوصمهن جميعا بهذا العار. } \\
& \text { وشعرت أن الله قد حازللصبيان في كل شيء. } 33
\end{aligned}
$$

Benarkah cara kotor seperti ini adalah satu-satunya jalan bagi para gadis untuk memasuki kedewasaan? Mungkinkah manusia bisa hidup selama beberapa hari di bawah

33 Nawal El Saadawi, Mudhakkirāt Ṭabībah, h. 8. kekuasaan otot ketidaksadarannya? Pastilah Tuhan tidak menyukai anak perempuan, sehingga Dia menyifatinya dengan aib ini. Aku merasa, Tuhan lebih berpihak kepada anak laki-laki dalam segala hal.

Persepsi buruk tentang menstruasi sebagai salah satu bentuk kebencian Tuhan terhadap anak perempuan, yang digambarkan El Saadawi melalui tokoh Aku bukan tanpa alasan. Menstruasi yang identik dengan keluarnya darah kotor dari tubuh perempuan setiap bulannya memunculkan banyak mitos yang mendiskriminasi perempuan. Secara ilmiah, Echendu Dolly Adimna dan J.I.B. Adimna dalam Perceptions and Practices on Menstruation Amongst Nigerian Secondary Schools Girls menerjemahkan menstruasi sebagai penanda awal masuknya perempuan pada fase pubertas, di mana organ-organ reproduksinya telah mencapai kematangan untuk sebuah proses reproduksi yang ditandai dengan perubahan drastis pada bentuk tubuh dan kondisi psikologis. Menstruasi dan siklus menstruasi ditandai dengan keanomalian dalam volume, pola, hormon, dan keteraturan dalam tubuh pada tahap awal yang mengakibatkan ketidaknyamanan emosional bagi perempuan. ${ }^{34}$ Meskipun banyak di antara gadis remaja dalam rentang usia 11-15 tahun telah mempersiapkan diri untuk menarche ${ }^{35}$ dengan berkonsultasi pada Ibu

34 Echendu Dolly Adimna dan J.I.B. Adimna, "Perceptions and Practices on Menstruation Amongst Nigerian Secondary Schools Girls," African Journal of Reproductive Health, Vol.12, No.1 (2008), h. 75.

35 Menarche adalah istilah untuk menstruasi pertama yang dialami seorang gadis remaja saat memasuki usia dewasa. Lihat, Shanbag D, dkk., "Perceptions regarding menstruation and Practices during menstrual cycles among high school going adolescent girls in resource limited settings around Bangalore city, Karnataka, India," International Journal of Collaborative Research on Internal Medicine \& Publik Health, Vol.4, No.7 (2012), h. 1354 
mereka, tetapi masih banyak gadis remaja yang enggan dan malu berkonsultasi pada orang tua maupun perempuan lain yang dianggap lebih mengerti tentang persoalan menstruasi, banyaknya paradigma negatif yang berkembang di masyarakat berkenaan dengan menstruasi bagi perempuan.

Selain menyoroti persoalan menstruasi, El Saadawi juga mengkritisi sistem kepengurusan akta nikah dalam kebudayaannya yang dianggapnya tidak berbeda dengan sistem jual beli ternak. Hanya saja, sistem ini telah dilegalkan dan dilindungi oleh ayat-ayat keagamaan. Pernikahan yang seyogyanya adalah ritual suci yang harus dimudahkan pelaksanaannya justru berkebalikan dalam praktiknya. Dalam masyarakat penganut patriarkis, pernikahan masih dipandang sebagai status, bukan sebagai kontrak yang harus terdapat persetujuan perempuan juga di dalamnya. Perempuan sebagai makhluk kedua yang terdistorsi keberadaannya harus menerima secara de facto statusnya yang tidak diperhitungkan dalam sebuah institusi pernikahan. Hal ini tergambar dalam narasi El Saadawi ketika tokoh Aku dan tokoh insinyur mengurus akta pernikahan mereka di lembaga pengurus pernikahan yang telah ditunjuk oleh pemerintah.

إناه فى يوم كذا يحضورى وعن يدي أنا فلان مأذون الجهة كذا التابعة المحكمة كذا للأحوال الشخصية تزوج فلان فلاناة على صيداق قدره كذا الحال منـا مبلغ والمؤجل منها مبلغ زواجا شرعيا على كتاب الله وسناة رسوله صل الله علياء وسلم بإيجاب وقبول شرعيين صادرين من الزوج المذكور وذلك بعد تعريفهما المعرفة الشرعية التحقق من خلو الطرفين

$$
\begin{aligned}
& \text { من كل مانع شرعى ونظامى والتحقق أيضيا أن الزوجة } \\
& \text { ليس لها معاش أو مرتب بالحكومة وليس لها مال يزيد } \\
& \text { على ما ئتى جنياء بشهادة كل من فلان وفلان. } 36
\end{aligned}
$$

"Pada hari ini, datang di hadapan saya... saya si anu, secara resmi merupakan pegawai pada pengadilan di sini... yang menangani masalah perdata... telah menikah si anu dengan si anu... dengan mas kawin sekian... jumlah yang kontan darinya sekian dan yang dihutang sekian... secara sah menurut al-Quran serta sunnah Rasulullah SAW... disertai serah-terima yang sah dari pihak suami. Pernikaahan ini berlangsung setelah keduanya saling mengenal dan tahu secara pasti bahwa keduanya terbebas dari segala halangan agama maupun sipil, dan si istri tidak mempunyai pendapatan ataupun gaji dari pemerintah, tidak pula ia memiliki harta lebih dari dua ratus pond, atas persaksian si anu dan si anu."

Posisi tawar tokoh Aku sebagai seorang perempuan mandiri, bekerja, dan berpenghasilan tinggi sama sekali tidak dipandang dalam institusi pernikahan. Hal ini menunjukkan bahwa perempuan dalam masyarakat patriarkis tetap dipandang sebagai the second sex, tak peduli apakah ia bisa hidup mandiri atau memang sepenuhnya bergantung pada laki-laki. Sebab pada dasarnya, budaya dan agama cenderung bersekongkol dalam membentuk streotipe negatif bagi perempuan. Salah satu di antara perihal yang melemahkan posisi perempuan dalam institusi pernikahan adalah sistem pembayaran mahar yang meskipun telah secara jelas diatur dalam Alquran dan Sunnah Nabi SAW, bahwa mahar adalah hadiah yang diberikan pihak lakilaki terhadap perempuan dan sepenuhnya 66. 
menjadi hak milik pribadi perempuan, justru berkebalikan dalam praktiknya.Pembayaran mahar yang seharusnya menjadi hak milik perempuan, dalam berbagai kebudayaan patriarkis yang sebagian di antaranya menganut agama Islam, justru menjadi hak milik orang tua atau keluarga lainnya yang diangggap sebagai upah lelah merawat. Sistem yang bias gender ini tak jarang berubah menjadi praktik human trafficking yang sangat merugikan perempuan, di mana orang tua/keluarga berusaha mendapatkan keuntungan pribadi melalui pembayaran mahar atau sekadar melunasi hutang piutang dengan menikahkan anak perempuannya pada lelaki kaya.

Hal lain yang tak luput dikritisi ElSaadawi dalam Mudhakkirât Thabîbah adalah persoalan mengenai pelecehan seksual, baik secara verbal maupun praktikal yang dialami tokoh Aku ketika masih kanak-kanak maupun setelah dewasa. Posisi perempuan sebagai second class citizen ${ }^{37}$ yang hak-hak individunya rentan penyalahgunaan dan penyalahartian, menjadikan perempuan dan anakperempuanlebihrawanuntukdijadikan sebagai objek pelecehan seksual dibanding laki-laki. ${ }^{38}$ L.M. Orange dan Bredwin M.G. sebagaimana dikutip Ira Paramastri, dkk., dalam Early Prevention Toward Sexual

37 Istilah second class citizen pertama kali digunakan oleh Buchi Emecheta dalam novelnya Second Class Citizen. Istilah ini diterjemahkan sebagai bentuk dari praktik diskriminasi gender dan peran tradisional laki-laki dan perempuan menurut jenis kelamin mereka. Dalam hal ini perempuan menjelma sebagai korban akibat seksisme akibat kegagalan budaya dalam mengidentifikasi anak perempuan sebagai individu yang sama dengan anak laki-laki. Lihat: Longjam Bedana dan Sangeeta Laishram, "Search for Identity and Home in Buchi Emecheta's novel Second Class Citizen," IOSR Journal Of Humanities And Social Science (IOSR-JHSS), Vol.19, No.5, Ver. VI (2014), h. 33.

38 V.L. Banyard, Williams, L.M., \& Siegel,J.A., "Childhood sexual abuse: A gender perspective on context \& consequences," Child Maltreatment, Vol.9, No.3 (2004), h. 224.
Abuse on Children mengklasifikasikan bentuk dan dampak pelecehan seksual pada perempuan dan anak-anak meliputi melihat, meraba, penetrasi (tekanan), pencabulan, dan pemerkosaan. Sedangkan dampak pelecehan seksual dapat berupa fisik, psikologis, dan sosial. Dampak secara fisik dapat berupa luka atau robek pada selaput dara. Dampak psikologi meliputi trauma mental, ketakutan, malu, kecemasan, bahkan keinginan untuk melakukan percobaan bunuh diri. Sedangkan dampak sosial dapat berupa perlakuan sinis dari masyarakat di sekelilingnya, ketakutan untuk terlibat dalam pergaulan, dan sebagainya. ${ }^{39}$ El Saadawi dalam hal ini mencoba memotret salah satu dari sekian banyak penyakit masyarakat yang seringkali tidak terungkap pada ranah publik hanya disebabkan oleh ketakutan maupun rasa malu akan persepsi negatif yang mungkin muncul di tengah publik.

Pelecehan seksual yang dialami tokoh Aku ketika masih berusia sepuluh tahun, dilakukan pertama kali oleh penjaga pintu rumahnya. Sebagaimana dinarasikan oleh El Saadawi, tokoh aku yang saat itu telah sampai usia balighnya yang ditandai dengan perubahan pada bentuk tubuh dan datangnyamenstruasiuntukpertamakalinya meski ia masih seorang gadis kecil berusia sepuluh tahun, tidak lagi bisa bergabung dalam permainan dengan saudara-saudara lelakinya. Ia mulai menyendiri karena malu terhadap perubahan bentuk tubuhnya yang tak bisa dikontrol dan dimengertinya. Pada suatu hari saat sedang asyik duduk menyendiri dekat taman bermain sambil memperhatikan saudara-saudara lelakinya bermain, melompat-lompat, berkejaran, sekonyong-konyong penjaga pintu

39 Ira Paramastri, dkk., "Early Prevention Toward Sexual Abuse on Children," Jurnal Psikologi, Vol.37, No.1 (2010), h. 2. 
yang memang tokoh Aku dan saudarasaudaranya takuti mendekatinya dengan tatapan garang dan penuh nafsu. Tokoh aku yang menyadari kehadiran si penjaga pintu berusaha menutupi ketakutannya dengan duduk menjauh dari jangkauan si penjaga pintu dan memusatkan perhatiannya pada saudara-saudaranya. Akan tetapi, si penjaga pintu yang telah tersulut nafsu tersebut terus mendekat dan memojokkan tokoh Aku.

$$
\text { والحسست أصابعـه الغليظة الخشنة تتحسس ساق }
$$

Tiba-tiba, kurasakan jari-jemarinyayang kasar mengelus-elus pahaku lalu menelusur ke atas di balik pakaianku. Aku meloncat ketakutan dan berlari menjauhinya. Rupanya lelaki hitam dan menakutkan ini pun telah menyadari ciri-ciri kewanitaanku.

Pelecehan seksual juga diterima tokoh Aku dari sepupunya sendiri (intrafamilial sexual abuse $)^{41}$ yang usia mereka tidak terpaut jauh. Hal ini tentunya menguatkan tesis bahwa pelecehan seksual terhadap 9.

40 Nawal El Saadawi, Mudhakkirāt Tabībah, h.

41 Pelecehan seksual intrafamilial adalah pelecehan seksual yang terjadi dalam keluarga (dilakukan oleh sesama anggota keluarga). Dalam bentuk pelecehan, anggota keluarga melibatkan anak (atau mengekspos anak untuk) dalam perilaku atau kegiatan seksual. Anggota keluarga di sini bukan hanya terbatas pada ayah, ibu, paman, saudara sepupu, kakek, dll. Tetapi juga orang lain yang sudah sangat dekat dengan keluarga seperti wali baptis dalam agama Kristen ataupun teman yang sangat dekat. Lihat, National Child Traumatic Stress Network, "Coping with the Shock of Intrafamilial Sexual Abuse," (2009). http://nctsn.org/nctsn assets/pdfs/caring/intrafamilialabuse.pdf, diakses 21 Januari 2016, pukul 16.23 WIB. anak rentan dilakukan oleh orang terdekat seperti ayah, paman, sepupu, kakek, paman, pembantu, dan lain-lain. Diceritakan dalam narasi El Saadawi, tokoh aku yang telah baligh suatu kali diajak keluar oleh sepupunya yang bisa dengan bebas keluar masuk kamarnya tanpa aba-aba terlebih dahulu. Keduanya bermain di luar rumah jauh dari jangkauan keluarganya, berkejaran seperti layaknya anak kecil yang belum dewasa tanpa peduli dengan kondisi tokoh Aku yang telah berbeda, hingga keduanya lelah dan memutuskan untuk tiduran di tanah memandangi langit cerah. Saat itulah tokoh Aku mulai menyadari pandangan berbeda dari tokoh sepupu. Gelagatnya yang aneh mengembalikan memori tokoh Aku pada tokoh penjaga pintu. Tokoh sepupu memandangi tokoh Aku dalam seolah ingin menyampaikan pemikirannya tentang birahi yang berkecamuk dalam dirinya:

$$
\text { بصوت غأيت ذراعه تمتد ناحية خصري ... وهمس فى أذنى }
$$

"Aku melihat tangannya menggapai ke arah pinggangku, dan dengan suara parau ia berbisik: 'aku akan menciummu'."

Menyikapi berbagai persoalan yang dihadapi perempuan akibat konstruksi timpang gender yang dilakukan oleh budaya dan laki-laki melaluimale's viewnya, El Saadawi melalui tokoh Aku sebagai pihak oposisional yang sedari awal dijelmakan bertentangan dengan berbagai bentuk tradisi dan kepercayaan patriarkis tersebut, menunjukkan keberaniannya untuk melawan berbagai gempuran arus kebudayaan dominan yang berlaku di lingkungannya dengan meningkatkan kesadaran akan keberadaan dirinya (erte pour soi) meski itu berarti harus dengan

42 Nawal El Saadawi, Mudhakkirāt Țabībah, h. 18-19. 
meliyankanoranglain. Sebagai pihak oposisi, perilaku tokoh Aku sejak masih belia telah menunjukkan sikap ketidaksetujuannya akan pandangan budaya mapan terhadap perempuan. Berbekal kesadaran diri yang dimilikinya serta hasrat untuk menjadi subjek yang eksistensinya tidak lagi hanya sebatas pelengkap laki-laki, tokoh Aku mengumpulkan keberaniannya dan berdiri sendiri melawan kelemahan dirinya, ibunya, keluarga, serta lingkungan dan budayanya.

Melalui narasi yang blak-blakan, apa adanya, serta sarat kebencian, El Saadawi benar-benar menciptakan tokoh perempuan pemberontak yang seolaholah menjadi penggambaran dirinya sendiri yang tidak takut terhadap apapun. Pertama, El Saadawi menunjukkan bahwa kesadaran bisamunculdalam diri seseorang khususnya perempuan disebabkan apa yang ia lihat dan alami di lingkungannya. Sejalan dengan konsep Beauvoir tentang kesadaran diri, El Saadawi menciptakan tokoh Aku kecil sebagai pemberontak yang tidak lagi tahan dengan perlakuanperlakuan diskriminatif yang diterimanya dari lingkungan, khususnya dari ibunya sendiri sebagai penggambaran perempuan yang telah hilang kesadaran dirinya dengan menerima eksistensi orang lain berkuasa dalam dirinya. Tokoh Aku kecil digambarkan memulai peperangannya saat dengan berani melanggar batas-batas yang telah ditetapkan secara mutlak di rumahnya dengan keluar tanpa izin, menolak perjodohan, dan memotong pendek rambutnya sebagai bentuk penegasan diri dan perlawanan terhadap aturan mutlak ibunya yang masih memegang kuat kepercayaan mengenai perempuan yang baik sebagaimana dikonstruksikan oleh masyarakatnya.
Kedua, selaras dengan munculnya kesadaran diri dalam diri seseorang untuk menjadi subjek yang tidak lagi teralienasi namun telah berubah menjadi pengalienasi, El Saadawi melalui tokoh Aku menawarkan bentuk perlawanan yang lebih riil yaitu dengan meningkatkan nilai diri melaluipendidikan. Keyakinan tersebut didasarkan pada kepercayaan bahwa pendidikan dapat membantu manusia memasuki dunia pencerahan dan peradaban dengan mengeluarkannya dari kegelapan baik secara fisik maupun psikis. $^{43}$ Selain itu, El Saadawi juga menggambarkan pendidikan sebagai bentuk pembuktian diri pada dunia bahwa perempuan dapat mengatasi keterbatasan dalam dirinya dengan segala paradigma negatif yang melekat dalam dirinya melaluiprestasi yang ditunjukkan dalam dunia pendidikan.

TokohAkumenyadaribahwa paradigma negatif yang selama ini berkembang dalam kebudayaannya tentang perempuan hanya dapat dipecahkan dengan mengonstruksi ulang dirinya dan berani tampil sebagai tipos perempuan baru yang tidak lagi terstigma oleh nilainilai mapan yang membesarkannya, namun telah menciptakan nilai-nilainya sendiri. Kebodohan hanya akan terus melemahkannya dan membawanya berbaur dalam pandangan yang sama dengan para perempuan bodoh dan buta huruf. Tidak hanya itu, tokoh Aku percaya bahwa kebodohan pulalah yang telah membawa perempuan pada ketidakadilan dan subordinasi yang terus hidup sepanjang zaman. Ilmu pengetahuan bagi tokoh Aku bukan hanya sebagai pemecah masalah pelik yang terjadi antara dirinya

43 Ita Rodiah, Perempuan dan Narasi dalam $K$ susasteraan Indonesia Kontemporer (Ciputat: Cinta Buku Media, 2014), h. 242. 
dengan kepercayaan di lingkungannya, tetapi ilmu pengetahuan jua telah memberi tahunya bahwa perempuan tidak berbeda dengan laki-laki. Seorang perempuan memiliki jantung yang sama dengan lakilaki dan dalam diri perempuan terdapat unsur lelaki begitu juga sebaliknya.

Ketiga, kesadaran diri dan pendidikan tinggi yang dimiliki tokoh Aku membawanya pada bentuk penegasan diri lainnya, yaitu dengan bekerja dan mendapatkan penghasilan. Dengan bekal kekuatan yang dimilikinya, tokoh Aku seperti terlahir kembali dalam bentukyang lebih baik dari sekadar perempuan lemah yang hanya bias berdiam diri ketika segala macam bentuk subordinasi dan intimidasi menekannya dari berbagai sudut. Pendidikan tinggi, pekerjaan terhormat, dan penghasilan yang besar bukan saja memberikan keberanian bagi tokoh Aku untuk melakukan perlawanan terhadap segala bentuk intimidasi dan subordinasi yang berusaha melemahkannya, tetapi juga telah memberinya rasa hormat dari berbagai golongan termasuk laki-laki. Dengan posisinya yang terhormat, tokoh Aku tak lagi memandang laki-laki sebagai jenis kelamin dominan yang dipenuhi segala bentuk keistimewaan dan dirinya hanyalah pelengkap bagi keistimewaan dan kekuasaan mereka, tetapi telah berbalik dengan menganggap dirinya sebagai Dewa yang dengan kekuatan dan ilmunya publik dengan tanpa banyak kata menerima mutlak setiap perkataan dan nasihat yang keluar dari mulutnya. Selain itu, tokoh aku juga seringkali membayang dirinya sebagai seseorang yang duduk di singgasana tinggi menikmati hasil dari segala bentuk perlawanannya dan memandang ke bawah pada masyarakat yang berada di kakinya dengan pandangan penuh iba. Baginya masyarakat, utamanya laki-laki tak ubahnya binatang mengerikan yang meraik batang leher perempuan ke dapur, tempat pemotongan daging, atau ke kuburan yang penuh lumpur. Dengan pendidikan, pekerjaan, dan penghasilan, betapa kecil tampaknya masyarakat yang dulunya penuh kuasa di mata tokoh Aku.

Berbeda dengan El Saadawi yang dalam narasinya hanya difokuskan pada kehidupan dan pandangan-pandangan sinis tokoh Aku tentang kehidupan dan relasi laki-laki dan perempuan yang telah dijejalinya dengan kecurigaan berlebihan terhadap budaya, agama dan masyarakat, STA dalam Layar Terkembang hadir menghidupkan pola relasi laki-laki dan perempuan yang berimbang, moderat, dan kompromisitas. Melalui tokoh Tuti, STA menggambarkan perempuan yang memperjuangkan persamaan haknya untuk hidup setara tak harus dilakukan dengan cara radikal seperti tokoh Aku yang memilih membuat garis yang jelas antara dirinya dengan lingkungan, masyarakat, dan keluarganya sendiri, tetapi bisa dilakukan dengan cara-cara yang lebih santun, berkelas, serta menggambarkan pribadi perempuan berpendidikan yang bijaksana.

Tokoh Tuti menjadi titik pusat dalam keseluruhan cerita dalam novel Layar Terkembang. Putri sulung Raden Wiriaatmaja ini digambarkan bukan hanya sebagai tokoh berpendirian kuat, tetapi juga penuh perhitungan dan cerdas. Gambaran sikap ini terlihat dari bab pembuka Layar Terkembang sebagai berikut:

Tuti bukan seorang yang mudah kagum, yang mudah heran melihat sesuatu. Keinsyafannya akan harga dirinya amat besar. Ia tahu bahwa ia pandai 
dan cakap serta banyak yang akan dapat dikerjakannya dan dicapainya. Segala sesuatu diukurnya dengan kecakapannya sendiri, sebab itu ia jarang memuji. Tentang apa saja ia mempunyai pemikiran dan pemandangan sendiri dalam segala buah pikirannya yang tetap itu berdasarkan pertimbangan yang disokong oleh keyakinann yang pasti. Jarang benar ia hendak lombarmelombar, turut menurut dengan orang lain, apabila sesuatu tiada sesuai dengan kata hatinya. ${ }^{44}$

Kegemarannya membaca dan pemikirannya yang out of the box menjadikan Tuti sebagai seorang aktivis perempuan paling berpengaruh dalam perkumpulannya, Putri Sedar. Tuti yang terlahir dari keluarga pribumi dan dibesarkan dalam didikan Barat sedikit banyaknya telah mempengaruhi logika berpikirnya. Sama seperti tokoh aku dalam novel Mudhakkirât Thabîbah-nya El Saadawi, Tuti juga percaya bahwa untuk bisa menjadi seorang yang dihargai eksistensi dan harga dirinya, perempuan harus cerdas dan berani keluar dari jangkar-jangkar yang telah dibangun laki-laki untuk mengikat dan memonopoli kemerdekaan perempuan, baik secara intelektual maupun itu urusan kehidupan sehari-hari. Meski tidak mudah untuk merubah paradigma masyarakat berkenaan dengan status sosial perempuan, STA melaui narasinya yang diwakilkan melaluitokoh Tuti tetap konsisten pada semangat awalnya membentuk perempuan baru yang modern dan ideal.

Meski terdapat persamaan besar dalam sikap Tuti dengan sikap tokoh Aku dalam Mudhakkirât Thabîbah, khususnya berkenaan dengan ide emansipasi dan kritik sosial terhadap otoritas agama

44 Sutan Takdir Alisjahbana, Layar Terkembang, (Jakarta: Balai Pustaka, 1936), h. 3-4. dan budaya dalam mendiskriminasi perempuan atas laki-laki, tetapi baik STA maupun El Saadawi masing-masing memiliki pemikiran tersendiri berkaitan dengan kepercayaan lama tentang public sphere dan private sphere. Jika tokoh aku dalam narasi El Saadawi digambarkan sebagai sosok perempuan yang membenci keperempuanan dan segala bentuk pekerjaan domestik yang selalu dinisbahkan kepada perempuan, maka berbeda halnya dengan Tuti. Tuti dalam narasi STA digambarkan bukan hanya sebagai perempuan yang cekatan dalam urusan pergerakan perempuan dan pekerjaan-pekerjaan lainnya di luar rumah, tetapi juga tetap sebagai perempuan yang tidak meninggalkan kodratnya sebagai perempuan yang sudah semestinya mampu mengurus keperluan domestik sebelum menyelarakan memperjuangkan emansipasi dan kesetaraan bagi perempuan. Sikap Tuti yang cekatan dalam urusan domestik dan publik digambarkan STA melalui sudut pandang ayah Tuti, Raden Wiriatmaja:

Meskipun banyak ia tiada mengerti perbuatan dan kegemarannya tetapi suatu pasal harus diakuinya: segala isi rumahnya beres sejak diselenggarakan oleh Tuti, jauh lebih beres dan rapi ketika mendiang istrinya masih hidup. Dan satu hal itu mendamaikan hatinya sebagai ayah kepada berbagai-bagai pekerti dan perbuatan anaknya itu yang tiada sesuai dengan pikirannya. Dalam hati kecilnya timbul suatu perasaan percaya, yang lahir oleh perasaan tiada kuasa untuk menunjukkan yang lebih baik, "Ah, Tuti tentu tahu sendiri, apa yang baik bagi dirinya." 45

\footnotetext{
45 Sutan Takdir Alisjahbana, Layar Terkembang,
} h. 14 . 
Tokoh Tuti sebagai tipos perempuan baru yang diciptakan STA sekilas memang tampak sebagai sosok perempuan yang egois, angkuh, dan membenci segala bentuk pelemahan teradap perempuan. Akan tetapi, ketika diteliti lebih lanjut, sikap tokoh Tuti dalam hal ini sangat berseberang dengan tokoh Aku meski mereka sama-sama memperjuangkan hal yang sama, yaitu hak bagi perempuan untuk mendapatkan perlakuan yang sama dengan laki-laki di ruang privat maupun di ruang publik. Ketidaksetujuan tokoh Tuti terhadap pandangan umum yang berlaku dalam masyarakat dan kebudayaan yang berlaku dan mengakar di negerinya tentang nilai-nilai negatif perempuan tidak lantas menjadikannya sebagai seorang perempuan yang berpandangan pesimis dan radikal. Tokoh Tuti memang memiliki beberapa kesamaan prinsip dengan tokoh Aku utamanya berkaitan dengan lelaki mana yang pantas untuk menjalin suatu hubungan cinta kasih dengannya, tentang prinsip untuk lebih memilih kehilangan sepenuhnya daripada mendapatkan sesuatu yang setengah-setengah. Namun ia tidak pernah membenci dirinya terlahir sebagai seorang perempuan layaknya tokoh Aku.

Dalam Layar Terkembang, STA tampaknya benar-benar menghadirkan suatu bentuk sastra bertendensi yang tidak hanya memberikan penghiburan semata bagi orang-orang, lebih-lebih melemahkan dan semakin menyudutkan pandangan orang berkenaan dengan tujuan yang hendak dicapai dalam penciptaan suatu karya sastra sebagaimana penggambaran kehidupan perempuan yang dinarasikan El Saadawi dalam Mudhakkirât Thabîbah. Sekilas El Saadawi memang terlihat bersemangat dalam menyuarakan bentuk- bentuk pelanggaran hak perempuan. Namun jika diteliti lebih seksama, narasinarasi El Saadawi justru lebih berpotensi memunculkan pandangan yang lebih negatif tentang perempuan. Melalui pandangan dunia El Saadawi, perempuan digambarkan begitu menyedihkan sampaisampai membenci tubuh dan kehidupannya sendiri sebagai penjelmaan dari segala halhal memalukan dalam hidup. Secara tidak sadar, El Saadawi melalui tokoh Aku benarbenar telah menciptakan sosok perempuan yang sepanjang hidupnya terbenani oleh kondisi keperempuanan yang ada dalam dirinya dan sosok perempuan yang hanya sibuk dengan dirinya sendiri dan tujuan-tujuan dari peperangan yang ingin dicapainya. Paradigma negatif yang berkembang dalam masyarakat tentang perempuan justru telah diinternalisasi El Saadawi secara utuh dan bulat-bulat dalam alam bawah sadarnya sehingga ia tidak hanya menciptakan perempuan ambisius dan selalu berprasangka negatif, tetapi juga telah menguatkan kepercayaan publik tentang lemah dan buruknya menjadi seorang perempuan.

Tidak seperti El Saadawi yang dengan tokoh Aku-nya hanya sibuk memandang dunia dari sudut pandangnya yang sinis dan pesimis, STA dalam Layar Terkembang menghidupkan sosok tokoh Tuti yang terbuka dengan segala bentuk diskusi dan masukan dari orang lain meski tak jarang ia mempunyai pandangan yang berbeda. Selain itu, tokoh Tuti juga bukanlah sosok perempuanyang hanya eksis di ruang publik namun sekonyong-konyong melupakan tugasnya di ruang privat. Melalui tokoh Tuti, STA memberikan gambaran bahwa tipos perempuan modern masa depan yang diingininya adalah mereka yang bisa berkarya dan memberikan kontribusi di 
ruang publik tanpa tidak harus melupakan tugasnya di ruang privat.

Pola relasi yang buruk antara lakilaki dan perempuan yang terjadi dalam masyarakat yang telah mengakar sejak jaman lampau tak lantas disikapi tokoh Tuti dengan pandangan yang negatif pula. Melalui berbagai diskusi dan rapatrapat dalam pergerakannya, tokoh Tuti melancarkan pandangan dan pendapatnya tentang bagaimana seharusnya menjadi perempuan. Masa lalu yang buruk dalam relasi laki-laki dan perempuan digambarkan tokoh Tuti sebagai contoh dan pemicu bagi perempuan untuk tampil menjadi sosok perempuan yang lebih baik. Perempuan yang tak lagi terdistorsi kediriannya namun telah memiliki keinsyafan tinggi akan harga dirinya.

Beberapa hal yang ditawarkan STA melalui tokoh Tuti dalam rangka merubah paradigma negatif masyarakat tentang perempuan adalah perempuan terlebih dahulu harus memiliki keinsyafan dan kesadaran akan harga dirinya. Perempuan harus cerdas, dan salah satu jalan untuk menjadi cerdas bagi perempuan adalah melalui jalur pendidikan dan menghilangkan tradisi buta huruf yang melekat pada perempuan. Tidak hanya berhenti di situ, STA juga menyarankan bahwa perempuan harus mempunyai pekerjaan dan penghasilan, dengan begitu laki-laki sebagai pihak dominan tidak lagi sibuk beranggapan bahwa perempuan hanya tahu bergantung pada laki-laki. Terakhir, perempuan tidak boleh ragu untuk terlibat aktif dalam kegiatankegiatan dan pergerakan yang hendaknya bisa memajukan potensi diri mereka yang dalam hal ini, perempuan tidak boleh ragu jika harus tampil sebagai penggerak suatu transformasi sosial dalam masyarakatnya.

\section{Simpulan}

Tokoh Aku sebagai tokoh sentral dalam novel Mudhakkirât Thabîbah digambarkan El Saadawi sebagai sosok oposisi yang memiliki kecenderung berlebih bahkan berseberangan dengan segala macam bentuk kebudayaan dan ajaran agama yang mengacu pada subordinasi terhadap perempuan. El Saadawi me-mandang permasalahan pelik yang diiringi pandangan-pandangan sinis dan curiga tokoh Aku terhadap institusi budaya dan agama seolah menjadi persoalan yang dihadapi semua perempuan di seluruh dunia. El Saadawi melalui tokoh Aku terkesan memaksakan pandangannya untuk diterima semua perempuan dengan berbekal pandangannya yang sinis bahwa budaya dan agama selalu bersekongkol membetuk subordinasi terhadap perempuan.

Berbeda dengan tokoh Aku yang cenderung curiga berlebihan terhadap budaya, agama, dan masyarakat dalam relasi laki-laki dan perempuan, tokoh Tuti dalam Layar Terkembang justeru hadir menghidupkan pola relasi laki-laki dan perempuan yang berimbang, moderat, dan penuh kompromi. Melalui tokoh Tuti, STA menarasikan perempuan yang memperjuangkan persamaan haknya untuk hidup setara tak harus dilakukan dengan cara radikal seperti tokoh Aku yang memilih membuat garis yang jelas antara dirinya dengan lingkungan, masyarakat, dan keluarganya sendiri, tetapi bisa dilakukan dengan cara-cara yang lebih santun, berkelas, serta menarasikan pribadi perempuan berpendidikan yang bijaksana. Tokoh Tuti memang memiliki beberapa kesamaan prinsip dengan tokoh Aku utamanya berkaitan dengan lelaki yang pantas untuk menjalin suatu 
hubungan cinta kasih dengannya, tentang prinsip untuk lebih memilih kehilangan sepenuhnya daripada mendapatkan sesuatu yang setengah-setengah. Namun ia tidak pernah membenci dirinya terlahir sebagai seorang perempuan layaknya tokoh Aku.

\section{Daftar Rujukan}

Adimna, Echendu Dolly dan J.I.B. Adimna. "Perceptions and Practices on Menstruation Amongst Nigerian Secondary Schools Girls." African Journal of Reproductive Health. Vol. 12, No. 1 (2008).

Ahmad, Sofe. "Sigmund Freud's Psychoanalityc Theory Oedipus Complex: A Critical Study With Reference to D.H. Lawrence's Son and Lovers," International Journal of English and literature, Vol. 3, No. 3 (2012).

Alisjahbana,SutanTakdir.LayarTerkembang. Jakarta: Balai Pustaka, 1936.

Aquinas, St. Thomas. Summa Theologica. Ohio: Benziger Bros, 1947.

Asiyanbola, Abidemi R. "Patriarchy, male dominance, the role and women empowerment in Nigeria." Paper submitted for presentation as poster at the International Union for the Scientific Study of Population (IUSSP/UIESP) XXV International Population Conference Tours, France, 2005.

B., Brummett. Techniques of Close Reading. Los Angeles: SAGE, 2010.

Banyard, V.L., Williams, L.M., \& Siegel,J.A., "Childhood sexual abuse: A gender perspective on context \& consequences." Child Maltreatment, Vol. 9, No. 3 (2004).

Bauer, Christian. "Stereotypical Gender
Roles and their Patriarchal Effects in A Streetcar Named Desire." http:// www.diva-portal.org/smash/get/ diva 2: 496855 / FULLTEXT 01.pdf (2012).

Bedana, Longjam dan Sangeeta Laishram. "Search for Identity and Home in Buchi Emecheta's novel Second Class Citizen." IOSR Journal of Humanities And Social Science (IOSR-JHSS), Vol. 19, No. 5, Ver. VI (2014).

Blevins, Carolyn DeArmond. Women in Christian History: A Bibliography. Macon, Georgia: Mercer Univ Press, 1995.

Bourdieau, Piere. Practical Reason: On the Theory of Action. California: Standford Unversity Press, 1998.

D., Shanbag. "Perceptions regarding menstruation and Practices during menstrual cycles among high school going adolescent girls in resource limited settings around Bangalore city, Karnataka, India." International Journal of Collaborative Research on Internal Medicine \& Publik Health, Vol. 4, No. 7 (2012).

Essien, Anthonia M. dan Donatus P. Ukpong. "Patriarchy and Gender Inequality: The Persistence of Religious and Cultural Prejudice in Contemporary Akwa Ibom State, Nigeria." International Journal of Social Science and Humanity. Vol. 2, No. 4 (2012).

Everingham, Christine. “Lacan's Gap: Sexual Identity and The Problem Connectednes.," Journal of Interdiciplinary Gender Studies, Vol. 1, No. 2 (1996).

Gardiner, Anne Barbeau. "Feminist Literary Criticism: From Anti-Patriarchy to Decadence." Modern Age, Vol. 49, No.4 (2007). 
Gounsolin, Margaret. “Women's Rights and Women's Rites: Religion at the Historical Root of Gender Stratification." Electronic Journal of Sociology (2005).

Hooks, Bell. "Feminism: A Movement to End Oppressions." dalam Anna Coote and Ters Gill (ed), Women's Rights: A Practical Guide. California: Penguin Books, 1974.

J., Charvet. Modern Ideologies: Feminism. London: J.M. Dent and Sons Limited, 1982.

Jóhannsdóttir, Nína Katrín. "Patriarchy and The Subordination of Women: From A Radical Feminist Point of View," Silligum Universitatis Islandiane (Mei, 2009).

Kamil, Sukron. Syari'ah Islam dan HAM: Dampak Perda Syari'ah terhadap Kebebasan Sipil, Hak-Hak Perempuan, dan Non-Muslim. Jakarta: CSRC, 2007.

Lines, Patricia M. "Shockling The Imagination: Education for Virtue in Plato and Rosseau." Humanitas, Vol.XXII, No.1-2 (2009): 40-68.

McDowell, L., dan Rosemary Pringle, Defining women: Social Institutions and Gender Divisions. Oxford: Polity Press, 1992.

Paramastri, Ira. "Early Prevention Toward Sexual Abuse on Children." Jurnal Psikologi. Vol. 37, No. 1 (2010).

Rodiah, Ita. Perempuan dan Narasi Dalam Kesusastraan Indonesia Kontemporer. Ciputat: Cinta Buku Media, 2014.
Rubin, Gayle. "The Traffic in Women: Notes on the 'Political Economy' of Sex." dalam Joan W. Scott (ed), Feminism and History. New York: Monthly Review Press, 1996.

Ruether, Rosemary Radford. "The Western Religious Tradition and Violence against Women in the Home." dalam Joanne Carlson Brown and Carole R. Bohn (ed), Christianity, Patriarchy, and Abuse. Cleveland, OH: Pilgrim, 1989.

Saadawi, Nawal El. Mudhakkirât Thabîbah. Beirut: Dâr al-Ma'ârif, 1960.

Saputra, Asep Deni. "Perempuan Subaltern dalam Karya Sastra Indonesia Poskolonial." Literasi, Vol. 1, No. 1 (2011).

Sudarnoto, Metodologi Penelitian Filsafat. Jakarta: Rajawali Press, 1996.

Sukidi, Teologi Inklusif Cak Nur. Jakarta: Kompas, 2008.

Sultana, Abeda. "Patriarchy and Women's Subordination: A Theoretical Analysis," The Art of Faculty Journal (Juli 2010Juni 2011).

Tong, Rosemary Putnam. Feminst Tought, Edisi Ke-3. USA: Westview Press, 2009.

Tracy, Steven R., "Pathriarchy and Domestic Violence: Challenging Common Misconception," JETS, Vol. 50, No. 3 (September, 2007). 